University of Wollongong

Research Online

Faculty of Engineering - Papers (Archive)

Faculty of Engineering and Information

Sciences

January 2011

\title{
Microwave hydrothermal synthesis of nano Co304 with various morphologies
}

Ben Niu

University of Jinan China

Liying Man

University of Jinan, Jinan

Jieqiang Wang

jiew@uow.edu.au

Follow this and additional works at: https://ro.uow.edu.au/engpapers

Part of the Engineering Commons

https://ro.uow.edu.au/engpapers/1641

\section{Recommended Citation}

Niu, Ben; Man, Liying; and Wang, Jieqiang: Microwave hydrothermal synthesis of nano Co304 with various morphologies 2011, 181-187.

https://ro.uow.edu.au/engpapers/1641

Research Online is the open access institutional repository for the University of Wollongong. For further information contact the UOW Library: research-pubs@uow.edu.au 
This article was downloaded by: [University of Wollongong]

On: 17 April 2012, At: 21:18

Publisher: Taylor \& Francis

Informa Ltd Registered in England and Wales Registered Number: 1072954 Registered office: Mortimer House, 37-41 Mortimer Street, London W1T 3J H, UK

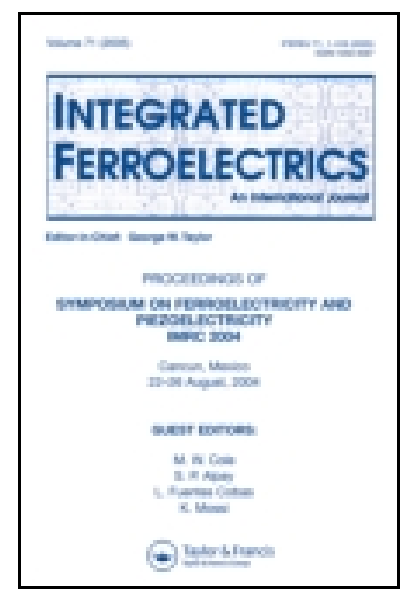

\title{
Integrated Ferroelectrics: An International J ournal
}

\author{
Publication details, including instructions for authors and \\ subscription information: \\ http:// www.tandfonline.com/ loi/ginf20
}

\section{Microwave Hydrothermal Synthesis of Nano $\mathrm{CO}_{3} \mathrm{O}_{4}$ with Various Morphologies}

\author{
Ben Niu ${ }^{a}$, Liying Man ${ }^{a} \&$ J ieqiang Wang ${ }^{a} b$ \\ a School of Materials Science and Engineering, University of J inan, \\ Jinan, 250022, P. R. China \\ ${ }^{b}$ Institute for Superconducting and Electronic Materials, University \\ of Wollongong, NSW, 2522, Australia
}

Available online: 17 Oct 2011

To cite this article: Ben Niu, Liying Man \& J ieqiang Wang (2011): Microwave Hydrothermal Synthesis

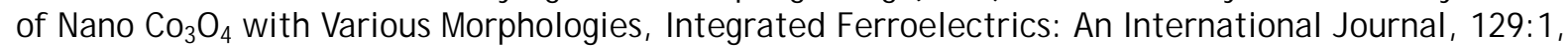
181-187

To link to this article: http:// dx.doi.org/ 10.1080/ 10584587.2011.576947

\section{PLEASE SCROLL DOWN FOR ARTICLE}

Full terms and conditions of use: http://www.tandfonline.com/page/terms-and-conditions

This article may be used for research, teaching, and private study purposes. Any substantial or systematic reproduction, redistribution, reselling, loan, sub-licensing, systematic supply, or distribution in any form to anyone is expressly forbidden.

The publisher does not give any warranty express or implied or make any representation that the contents will be complete or accurate or up to date. The accuracy of any instructions, formulae, and drug doses should be independently verified with primary sources. The publisher shall not be liable for any loss, actions, claims, proceedings, demand, or costs or damages whatsoever or howsoever caused arising directly or indirectly in connection with or arising out of the use of this material. 


\title{
Microwave Hydrothermal Synthesis of Nano $\mathrm{Co}_{3} \mathrm{O}_{4}$ with Various Morphologies
}

\author{
BEN NIU,${ }^{1}$ LIYING MAN,${ }^{1}$ AND JIEQIANG WANG ${ }^{1,2, *}$ \\ ${ }^{1}$ School of Materials Science and Engineering, University of Jinan, \\ Jinan 250022, P.R. China \\ ${ }^{2}$ Institute for Superconducting and Electronic Materials, \\ University of Wollongong, NSW 2522, Australia
}

\begin{abstract}
The precursors with various morphologies including nanowires, nanosheets, and hexagonal nanoplatelets were synthesized under different conditions by the microwave hydrothermal method. The precursors are transformed into $\mathrm{Co}_{3} \mathrm{O}_{4}$ with various nanostructures through thermal decomposition. It is very important to synthesize the precursors controlling the microwave hydrothermal conditions, such as the mineralizer, the reaction temperature, and the reaction time. The microwave assisted hydrothermal approach presented here opens a potential avenue to explore the synthesis of various other metal oxides with different nanomorphologies.
\end{abstract}

Keywords $\mathrm{Co}_{3} \mathrm{O}_{4}$; morphology; nanostructrure; microwave hydrothermal synthesis

\section{Introduction}

$\mathrm{Co}_{3} \mathrm{O}_{4}$ has a wide range of applications in varistor ceramics, catalysts, sensors, electrochemical materials, and magnetic materials, and the particle size and morphology of $\mathrm{Co}_{3} \mathrm{O}_{4}$ have a significant effect on the physical and chemical properties [1-2]. Recently, more and more attention has been paid to the control of the morphologies and microstructures of nanomaterials. So a variety of methods [3-5], such as chemical spray pyrolysis, liquid-control-precipitation, and sol-gel method, etc, have been used to prepare special morphology of nanosized $\mathrm{Co}_{3} \mathrm{O}_{4}$, to enhance surface area and electrochemical reactivity. Therefore, the electrochemical performance of $\mathrm{Co}_{3} \mathrm{O}_{4}$ with small particle size and special textural characteristics, especially, one-dimensional (1-D), such as porous $\mathrm{Co}_{3} \mathrm{O}_{4}$ nanotubes $[6,7]$, and nanowires/nanorods [8, 9], etc., has recently been widely explored using various template-synthesis methods.

We present here a novel microwave-assisted hydrothermal synthesis approach that offers nanosized $\mathrm{Co}_{3} \mathrm{O}_{4}$. The methods take advantage of both the microwave irradiation and the hydrothermal effect to offer products with controlled shapes, sizes, and structures within a short reaction time. That is, we not only prepare one-dimensional (1-D) $\mathrm{Co}_{3} \mathrm{O}_{4}$ nanowires, but also two-dimensional (2-D) $\mathrm{Co}_{3} \mathrm{O}_{4}$ macroporous nanosheets and hexagonal nanoplatelets were obtained.

Received July 15, 2010; in final form August 24, 2010.

*Corresponding author. E-mail: mse_wangjq@ujn.edu.cn 


\section{Experiments}

\subsection{Materials Preparation}

All of the chemical reagents were of analytical grade and used without further purification. The experimental details are as follows: $0.021 \mathrm{~mol} \mathrm{Co}\left(\mathrm{NO}_{3}\right)_{2} \cdot 6 \mathrm{H}_{2} \mathrm{O}$ was dissolved in $100 \mathrm{ml}$ distilled water under stirring, and $0.168 \mathrm{~mol} \mathrm{CO}\left(\mathrm{NH}_{2}\right)_{2}$ was introduced into the abovementioned solution. Then, $10 \mathrm{mmol} \mathrm{Co}\left(\mathrm{NO}_{3}\right)_{2} \cdot 6 \mathrm{H}_{2} \mathrm{O}$ was dissolved in $50 \mathrm{ml}$ distilled water under stirring, and $2 \mathrm{M} \mathrm{KOH}$ solution was introduced into the above-mentioned solution at a rate of $2 \mathrm{~mL} \cdot \mathrm{min}^{-1}$, until the $\mathrm{pH}$ value of the solution reached 11 . The above milky solution was stirring after $30 \mathrm{~min}$, respectively, then, transferred into a double-walled vessel. The vessel was sealed and maintained in a Microwave Accelerated Reaction System (MARS-5, CEM Corporation, USA) at $110^{\circ} \mathrm{C}$ for $1 \mathrm{~h}, 140^{\circ} \mathrm{C}$ for $3 \mathrm{~h}$, and $140^{\circ} \mathrm{C}$ for $3 \mathrm{~h}$, respectively. After the reaction finished, the resultant black precipitates were centrifuged, washed with distilled water and then ethanol to minimize the extra ions in the final products, and dried at $80^{\circ} \mathrm{C}$ in air. Finally, the powders were calcinated at $350^{\circ} \mathrm{C}$ and $500^{\circ} \mathrm{C}$ in air for $2 \mathrm{~h}$, respectively.

\subsection{Materials Characterization}

The morphology and structure of the as-prepared samples were characterized by powder X-ray diffraction (XRD, GBC MMA, Cu K $\alpha$ radiation, $40 \mathrm{kV}, 25 \mathrm{~mA}$ ), field emission scanning electron microscopy (FESEM, JEOL JSM7500FA, $15 \mathrm{kV}$ ), transmission electron microscopy (TEM), high-resolution TEM (HRTEM) and selected area electron diffraction (SAED) (JEOL 2011F, $200 \mathrm{kV}$ ).

\section{Results And Discussion}

XRD pattern in Fig. 1 shows that the precursor processed by microwave irradiation consists of cobalt-basic-carbonate compounds and cobalt(II) hydroxide. In these precipitations, a sudden burst of nuclei occurred when the temperature was raised and the nuclei subsequently were grown into larger crystallites by an aggregation mechanism. The XRD pattern show characteristics of the cobalt-basic-carbonate phase, which is agreement with the reported compound, $\mathrm{Co}(\mathrm{OH})_{1.0}\left(\mathrm{CO}_{3}\right)_{0.5} \cdot 0.11 \mathrm{H}_{2} \mathrm{O}$, with lattice constants $\mathrm{a}=8.79 \AA \mathrm{A}, \mathrm{b}=$ $10.15 \AA$, and $\mathrm{c}=4.43 \AA$ (JCPDS card No. 48-0083) [10-12], and the brucite-like $\beta$ $\mathrm{Co}(\mathrm{OH})_{2}$ (JCPDS card No. 30-0443, hexagonal crystal, space group: P-3m1, a = 3.183 $\mathrm{c}=4.652 \AA$ ) was the predominant phase. The other possible precipitates, such as $\mathrm{CoCO}_{3}$, $\mathrm{Co}(\mathrm{OH}) \mathrm{x}(\mathrm{NO})_{2-\mathrm{x}} \cdot \mathrm{nH}_{2} \mathrm{O}$, etc, were not detected (verified by XRD analysis).

Figure 2 shows the XRD patterns of the samples, and the peaks in the XRD spectra are identical and can be perfectly indexed as cubic spinel $\mathrm{Co}_{3} \mathrm{O}_{4}$ phase. All reflection peaks at (111), (220), (311), etc., can be indexed to the peaks of the $\mathrm{Co}_{3} \mathrm{O}_{4}$ phase, which are consistent with the values in the standard card (JCPDS Card No. 42-1467), agree very well with the literature data [13]. No peaks from other phases have been detected, indicating that the products are of high purity.

From Fig. 3 (a), it can be seen that a large quantity of nanorods with a diameter of $60-100 \mathrm{~nm}$ and an edge length beyond $1 \mu \mathrm{m}$ were obtained. The wire-like precursor was synthesized due to the domination of $\mathrm{CO}_{3}{ }^{2-}$ anion at $110^{\circ} \mathrm{C}$ for $1 \mathrm{~h}$ under microwave irradiation. The incorporated carbonate anions change the crystal structure and morphology of generated basic compounds. During the growth of compound, the carbonate anions may 


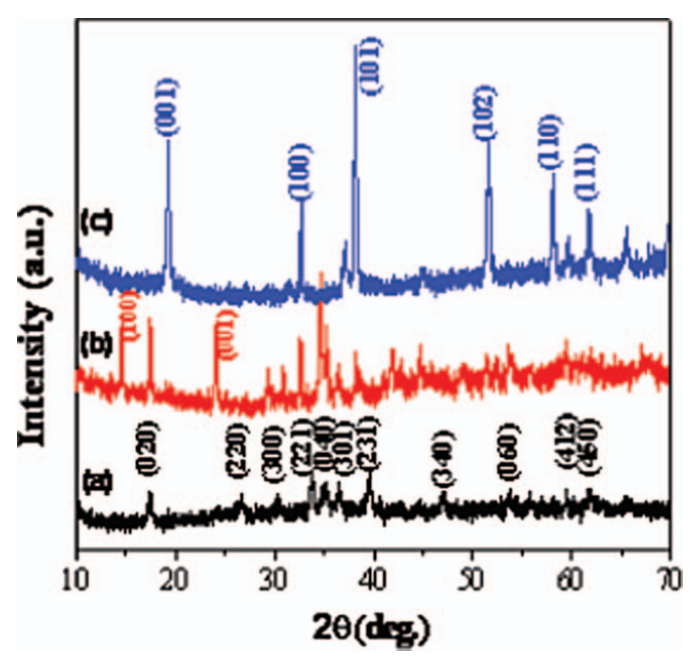

Figure 1. XRD patterns of precursor generated under different microwave irradiation conditions: (a) at $110^{\circ} \mathrm{C}$ for $1 \mathrm{~h}$, using urea as mineralizer; (b) at $140^{\circ} \mathrm{C}$ for $3 \mathrm{~h}$, using urea as mineralizer; (c) at $140^{\circ} \mathrm{C}$ for $3 \mathrm{~h}$, using potassium hydroxide as mineralizer.

also act as an inhibitor that selectively decreases the rates of crystal growth along one direction, resulting in the long nanorods. Moreover, it can be seen that the size and shape of the $\mathrm{Co}_{3} \mathrm{O}_{4}$ nanowires are similar to those of the cobalt-basic-carbonate precursors. From Fig. 3 (b) and (c), we can see that many nanoparticles are selfassembled into nanochains and then the nanochains are assembled into a bundle of the uniform thin wires-like $\mathrm{Co}_{3} \mathrm{O}_{4}$. Furthermore, the $\mathrm{Co}_{3} \mathrm{O}_{4}$ nanowires calcined at $500^{\circ} \mathrm{C}$ for $2 \mathrm{~h}$ developed perfectly.

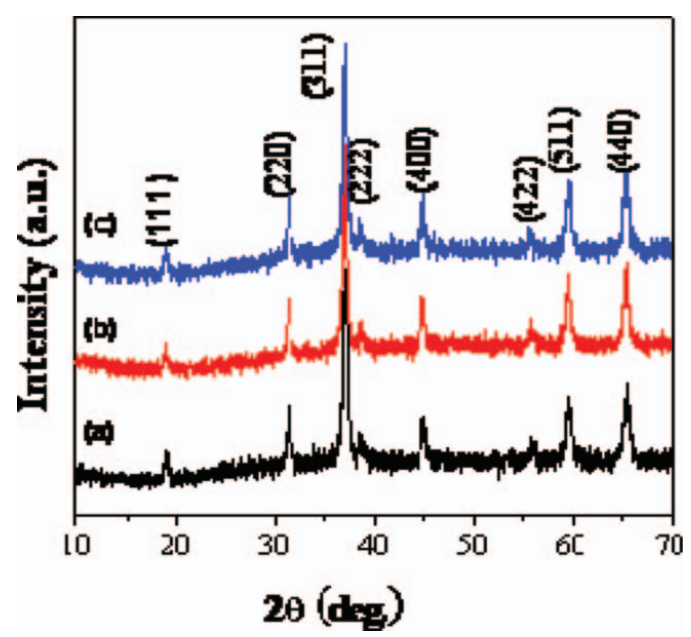

Figure 2. XRD patterns of $\mathrm{Co}_{3} \mathrm{O}_{4}$ samples calcined at $350^{\circ} \mathrm{C}$ for $2 \mathrm{~h}$ from precursors generated under different microwave irradiation conditions: (a) at $110^{\circ} \mathrm{C}$ for $1 \mathrm{~h}$, using urea as mineralizer; (b) at $140^{\circ} \mathrm{C}$ for $3 \mathrm{~h}$, using urea as mineralizer; (c) at $140^{\circ} \mathrm{C}$ for $3 \mathrm{~h}$, using potassium hydroxide as mineralizer. 

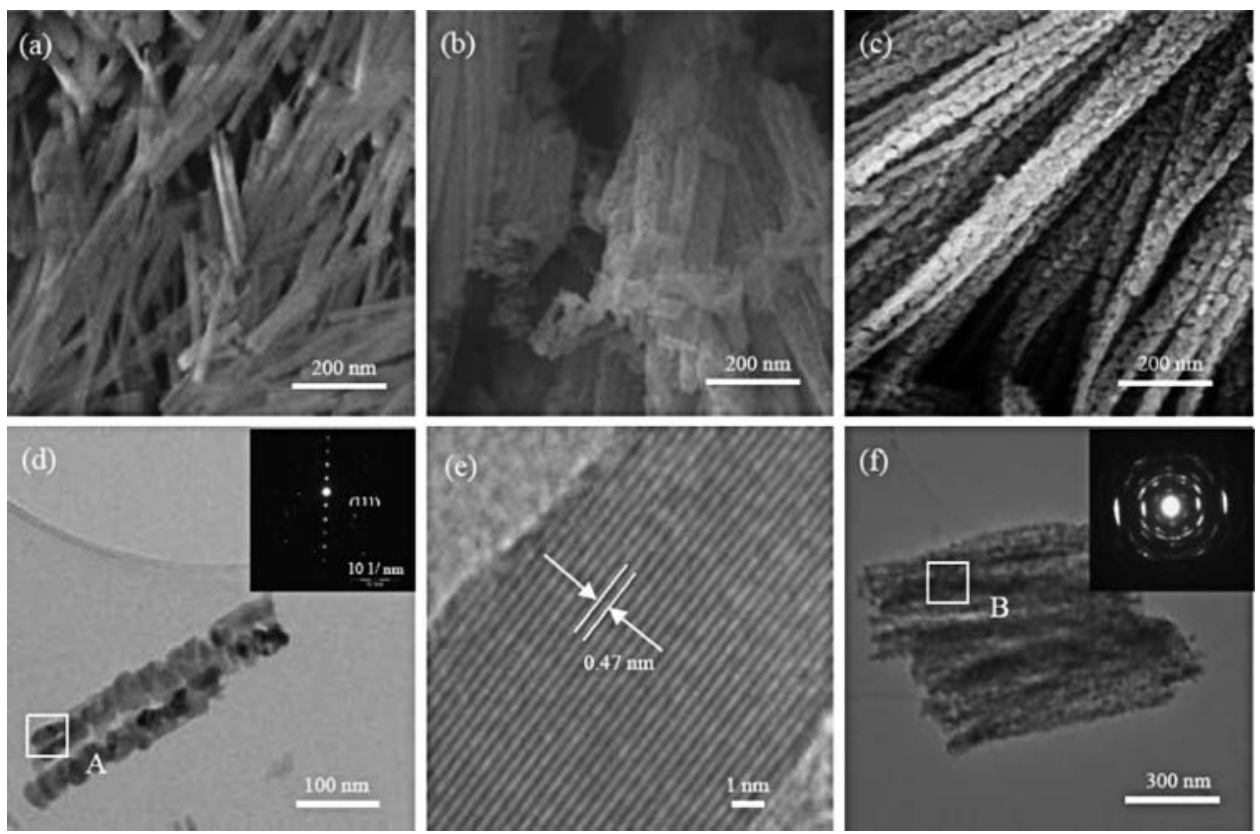

Figure 3. Morphological and structural characterizations of cobalt-basic-carbonate compounds generated under at $110^{\circ} \mathrm{C}$ for $1 \mathrm{~h}$ using urea as mineralizer, and $\mathrm{Co}_{3} \mathrm{O}_{4}$ nanowires by subsequent calcination: (a) FESEM image of precursor; (b) FESEM images of $\mathrm{Co}_{3} \mathrm{O}_{4}$ at $350^{\circ} \mathrm{C}$ for $2 \mathrm{~h}$; (c) FESEM images of $\mathrm{Co}_{3} \mathrm{O}_{4}$ at $500^{\circ} \mathrm{C}$ for $2 \mathrm{~h}$; (d) TEM image of nanowire array, inset is corresponding SAED patterns of A; (e) HRTEM image of a typical individual $\mathrm{Co}_{3} \mathrm{O}_{4}$ nanocrystal of site A; (f) TEM image of nanowire array, inset is corresponding SAED pattern.

Figure 3(d) and (e) are typical TEM images of $\mathrm{Co}_{3} \mathrm{O}_{4}$ nanowire at relatively high magnification, and Fig. 3(f) is at relatively low magnification. The inset in Fig. 3(d) is the SAED patterns (Selected Area Electron Diffraction Pattern) of the sample. The HRTEM image (Fig. 3(e)) indicates a highly crystalline character with a lattice spacing of $4.7 \AA$, corresponding to the value of the (111) plane of the $\mathrm{Co}_{3} \mathrm{O}_{4}$ phase. We select an area as shown
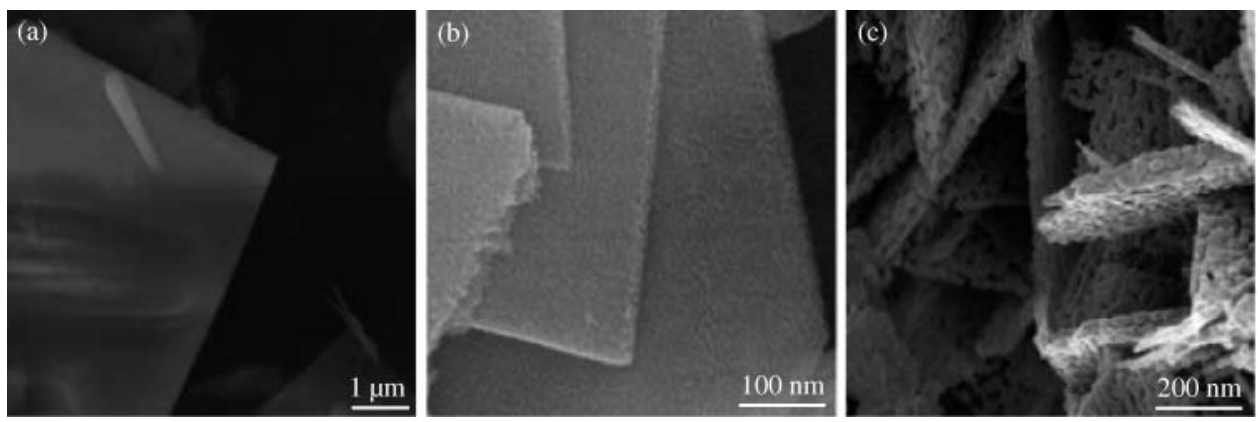

Figure 4. Morphological and structural characterizations of cobalt-basic-carbonate compounds generated under at $140^{\circ} \mathrm{C}$ for $3 \mathrm{~h}$ using urea as mineralizer, and $\mathrm{Co}_{3} \mathrm{O}_{4}$ nanowires by subsequent calcination: (a) FESEM image of precursor; (b) FESEM image of $\mathrm{Co}_{3} \mathrm{O}_{4}$ at $350^{\circ} \mathrm{C}$ for $2 \mathrm{~h}$, (c) FESEM images of $\mathrm{Co}_{3} \mathrm{O}_{4}$ at $500^{\circ} \mathrm{C}$ for $2 \mathrm{~h}$. 
in Fig. 3 (f), the SAED patterns prove that the $\mathrm{Co}_{3} \mathrm{O}_{4}$ nanowires is crystal texture. $\mathrm{Co}_{3} \mathrm{O}_{4}$ nanowires are composed of numerous nanoparticles, with a diameter about 10-20 nm. The porous nature of the $\mathrm{Co}_{3} \mathrm{O}_{4}$ nanowires is also further confirmed by TEM, which differs from that of the precursors and may greatly increase the surface area of $\mathrm{Co}_{3} \mathrm{O}_{4}$ nanowires.

From Fig. 4(a), We can see that the precursors are typical nanosheets. The platelet-like precursor was synthesized due to the domination of $\mathrm{OH}^{-1-}$ anion at $140^{\circ} \mathrm{C}$ for $3 \mathrm{~h}$ under microwave irradiation. With increasing reaction temperature and time, the urea hydrolysis is improved rapidly the $\mathrm{pH}$ value of the solution is increased, and then the carbonate anions in the compound are partially substituted by hydroxyl groups [14]. The orientational growing
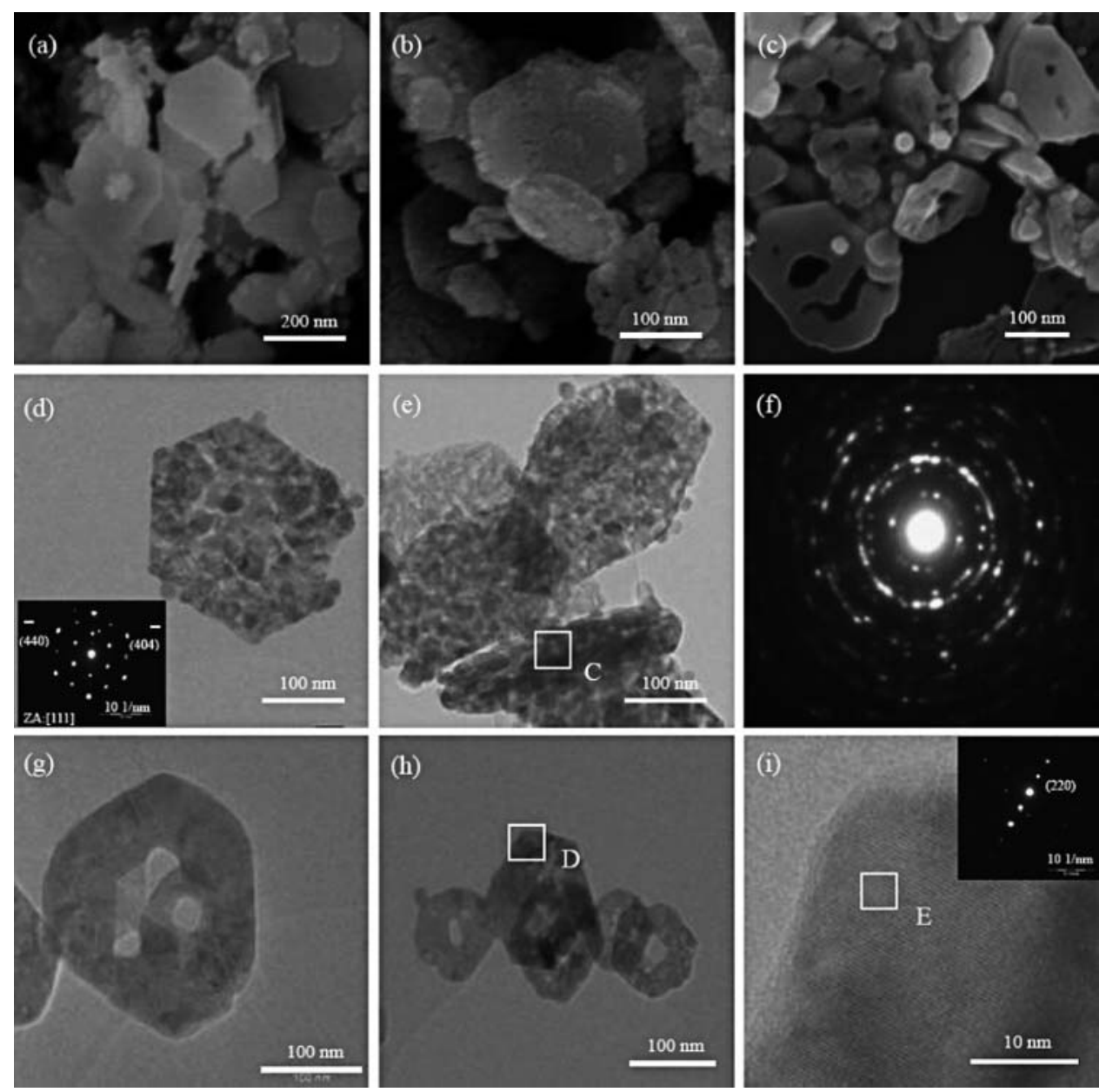

Figure 5. Morphological and structural characterizations of $\beta-\mathrm{Co}(\mathrm{OH})_{2}$ nanoplatelets generated under $140^{\circ} \mathrm{C}$ for $3 \mathrm{~h}$ using potassium hydroxide as mineralizer,and $\mathrm{Co}_{3} \mathrm{O}_{4}$ nanoplates by subsequent calcination: (a) FESEM image of precursor; (b) FESEM image of $\mathrm{Co}_{3} \mathrm{O}_{4}$ at $350^{\circ} \mathrm{C}$ for $2 \mathrm{~h}$, (c) FESEM image of $\mathrm{Co}_{3} \mathrm{O}_{4}$ at $500^{\circ} \mathrm{C}$ for $2 \mathrm{~h}$; (d) TEM image of a typical individual hexagonal nanoplatelet, inset is corresponding SAED patterns; (e) TEM image of $\mathrm{Co}_{3} \mathrm{O}_{4}$ nano nanoplatelets; (f) image of SAED pattern of C; (g) TEM image of a typical individual hexagonal nanoring; (h) TEM image of $\mathrm{Co}_{3} \mathrm{O}_{4}$ nano nanorings; (i) HRTEM image of $\mathrm{Co}_{3} \mathrm{O}_{4}$ nanocrystal of corner $\mathrm{D}$, inset is corresponding SAED pattern of $\mathrm{E}$. 
tendency of the compound dominated by carbonate anions is weakened at $140^{\circ} \mathrm{C}$ for $3 \mathrm{~h}$ under microwave irradiation, so the initial nanowires aggregate side-by-side and finally form a large platelet. So we can see that, the morphologies of the precursor have a dramatic change with the temperature elevated. Furthermore, compared to Fig. 4 (b) and (c), the $\mathrm{Co}_{3} \mathrm{O}_{4}$ nanoplatelets calcined at $350^{\circ} \mathrm{C}$ have relatively small nanoparticles, however the $\mathrm{Co}_{3} \mathrm{O}_{4}$ nanoplatelets have big nanoparticles when they are calcined at $500^{\circ} \mathrm{C}$. Above all, it is very important to synthesize the precursors with some experimental parameters, such as the reaction temperature and the calcination temperature.

From Fig. 5 (a), We can see that most platelets have an approximately hexagonal morphology, which structure enhanced due to high basicity. It is well known that the brucitelike $\beta-\mathrm{Co}(\mathrm{OH})_{2}$ has a layered structure comprised of sheets of hexagonally close-packed $\mathrm{OH}$ ions with $\mathrm{Co}$ (II) bonded to the six $\mathrm{OH}$. The sheets are parallel to the (001) plane. These $\mathrm{Co}(\mathrm{OH})_{2}$ sheets are bonded to one-another by weak $\mathrm{OH}-\mathrm{OH}$ dipole interactions. Therefore, brucite crystals have the tendency to grow into thin hexagonal nanoplatelets [15-16]. From Fig. 5 (b) and (c), the $\mathrm{Co}_{3} \mathrm{O}_{4}$ resultants after the calcinations with a thickness of 20-30 nm and an edge length between $100-200 \mathrm{~nm}$ are similar to those of the $\beta-\mathrm{Co}(\mathrm{OH})_{2}$ precursor. With increasing the calcination temperature from $350^{\circ} \mathrm{C}$ to $500^{\circ} \mathrm{C}$, the porous $\mathrm{Co}_{3} \mathrm{O}_{4}$ from hexagonal platelets and then to $\mathrm{Co}_{3} \mathrm{O}_{4}$ rings.

Figure $5(\mathrm{~d})$ is a typical hexagonal nanoplatelets, inset it is a SAED pattern, exhibiting the hexagonal structures of brucite-like $\beta$-cobalt hydroxides. Figure 5(f) exhibits SAED pattern of $\mathrm{C}$, the $\mathrm{Co}_{3} \mathrm{O}_{4}$ nanoplatelets have a tendency to polycrystalline in nature. It can be seen from Fig. 5 (d) and (g), the porous vary in size associated with different calcination temperature. The inset in Fig. 5(i) is the corresponding electron diffraction (ED) pattern of the $\mathrm{Co}_{3} \mathrm{O}_{4}$ platelet. The HRTEM image confirms the $\mathrm{Co}_{3} \mathrm{O}_{4}$ rings structure with a lattice spacing of $2.8 \AA$, in accordance with the (220) plane of many $\mathrm{Co}_{3} \mathrm{O}_{4}$ single nanocrystals. This further reveals that the nanoplatelets grow in an oriented manner to form an integrated porous architecture with interesting combined properties of porosity and quasi-singlecrystallinity. The $\beta$ - $\mathrm{Co}(\mathrm{OH})_{2}$-to- $\mathrm{Co}_{3} \mathrm{O}_{4}$ transition is known as a topotactic transformation [17-19]. The hollow nature of the $\mathrm{Co}_{3} \mathrm{O}_{4}$ ring might be caused by the Kirkendall effect, in which an inward flow of vacancies, balancing the outward transport of fast-moving cations, can condense into voids at the centre of the ring.

\section{Conclusions}

In summary, we have demonstrated a simple microwave-assisted homogeneous precipitation approach to synthesize cobalt-basic-carbonate compounds and cobalt(II) hydroxide. Furthermore, the dimension and morphology of the synthesized precursor compounds can be tailored due to the change of the incorporated anions $\left(\mathrm{CO}_{3}{ }^{2-}\right.$ and $\left.\mathrm{OH}^{-1}\right)$ by controlling the temperature and time under microwave irradiation.

With increasing the calcination temperature from $350^{\circ} \mathrm{C}$ to $500^{\circ} \mathrm{C}$, the precursor compounds are transformed into porous samples, such as, the morphology and fabric of samples changes from rods-like precursor to $\mathrm{Co}_{3} \mathrm{O}_{4}$ nanowires, platelet-like precursor to $\mathrm{Co}_{3} \mathrm{O}_{4}$ macroporous nanosheets, hexagonal platelet-like precursor to $\mathrm{Co}_{3} \mathrm{O}_{4}$ porous platelet then to rings.

\section{Acknowledgments}

This work was supported by the Foundation for Excellent Middle-aged or Young Scientists from Shandong Province under Grant No.BS2009CL029 and the Australian Research Council through a Discovery Project (project ID: DP0878611). 


\section{References}

1. D. Barreca, C. Massignan, S. Daolio, M. Fabrizio, C. Piccirillo, L. Armelao, and E. Tondello, Composition and microstructure of cobalt oxide thin films obtained from a novel cobalt(II) precursor by chemical vapor deposition. Chem. Mater. 13, 588-593 (2001).

2. X. Wang, X. Chen, L. Gao, H. Zheng, Z. Zhang, and Y. T. Qian, One-dimensional arrays of $\mathrm{Co}_{3} \mathrm{O}_{4}$ nanoparticles: synthesis, characterization, and pptical and electrochemical properties. J. Phys. Chem. B. 108, 16401-16404 (2004).

3. J. Hu, T. W. Odom, and C. M. Lieber, Chemistry and physics in One dimension:synthesis and properties of nanowires and nanotubes. Acc. Chem. Res. 32, 435-445 (1999).

4. J. Goldberger, R. R. He, Y. F. Zhang, S. K. Lee, H. Q. Yan, H. J. Choi, and P. D. Yang, Singlecrystal gallium nitride nanotubes. Nature 422, 599-602 (2003).

5. W. Ting, Y. W. Zhu, X. J. Xu, Z. X. Shen, P. Chen, C. H. Lim, J. T. L. Thong, and C. H. Sow, Controlled growth and fild-emission properties of cobalt oxide nanowalls. Adv. Mater. 17, 1595-1599 (2005).

6. R. M. Wang, C. M. Liu, H. Z. Zhang, C. P. Chen, L. Guo, H. B. Xu, and S. H. Yang, Porous nanotubes of $\mathrm{Co}_{3} \mathrm{O}_{4}$ : synthesis, characterization and magnetic properties. Appl. Phys. Lett. 85, 2080-2082 (2004).

7. T. Li, S. G. Yang, L. S. Huang, Gu B X, and Y. W. Du, A Novel process from cobalt nanowire to $\mathrm{Co}_{3} \mathrm{O}_{4}$ nanotube. Nanotechnology 15, 1479-1482 (2004).

8. B. Z. Tian, X. Y. Liu, H. F. Yang, S. H. Xie, C. Z. Yu, B. Tu, and D. Y. Zhao, General synthesis of ordered crystallized metal oxide nanoarrays replicated by microwave-digested mesoporous silica. Adv. Mater. 15, 1370-1374 (2003).

9. E. L. Salabas, F. Rumplecker, F. Kleitz, F. Radu, and F. Schuth, Exchange anisotropy in nanocasted $\mathrm{Co}_{3} \mathrm{O}_{4}$ nanowires. Nano Lett. 6, 2977-2981 (2006).

10. R. Xu and H. C. Zeng, Dimensional control of cobalt-hydroxide-carbonate nanorods and their thermal conversion to one-dimensional arrays of $\mathrm{Co}_{3} \mathrm{O}_{4}$ nanoparticles. J. Phys. Chem. B. 107, 12643-12649 (2003).

11. L. H. Hu, Q. Peng, and Y. D. Li, Selective synthesis of $\mathrm{Co}_{3} \mathrm{O}_{4}$ nanocrystal with different shape and crystal plane effect on catalytic property for methane combustion. J. Am. Chem. Soc. 130, 16136-16137 (2008).

12. P. Porta, R. Dragone, G. Fierro, M. Inversi, M. Lojacono, and M. Giuliano, Preparation and characterisation of cobalt-copper hydroxysalts and their oxide products of decomposition. J Chem Soc., Faraday Trans. 88, 311-319 (1992).

13. J. Q. Wang, G. D. Du, Z. Rong, B. Niu, Z. X. Chen, Z. P. Guo, and S. X. Dou, Porous $\mathrm{Co}_{3} \mathrm{O}_{4}$ nanoplatelets by self-supported formation as electrode material for lithium-ion batteries. Electrochimica Acta. 55, 4805-4811 (2010).

14. J. Q. Wang, S. H. Zhen, R. Zeng, S. X. Dou, and X. D. Sun, Microwave synthesis of homogeneous YAG nanopowder leading to a transparent ceramic. J. Am. Ceram. Soc. 92: 1217-1223 (2009).

15. Y. L. Hou, H. Kondoh, M. Shimojo, T. Kogure, and T. Ohta, Anomalous decrease of the work function of a carbide-modified W(110) surface induced by hydrogen chemisorption. J. Phys. Chem. B. 109, 19094-19098 (2005).

16. X. W. Xie, Y. Li, Z. Q. Liu, M. Haruta, and W. J. Shen, Low-temperature oxidation of CO catalysed by $\mathrm{Co}_{3} \mathrm{O}_{4}$ nanorods. Nature 458, 746-749 (2009).

17. X. W. Lou, D. Deng, J. Y. Lee, J. Feng, and L. A. Archer, Self-supported formation of needlelike $\mathrm{Co}_{3} \mathrm{O}_{4}$ nanotubes and their application as lithium-ion batteries electrodes. Adv. Mater. 20, 258-262 (2008).

18. Y. G. Li, B. Tan, and Y. Y. Wu, Freestanding mesoporous quasi-single-crystalline $\mathrm{Co}_{3} \mathrm{O}_{4}$ nanowire arrays. J. Am. Chem. Soc. 128, 14258-14259 (2006).

19. E. Hosono, S. Fujihara, I. Honma, and H. S. Zhou, Superhydrophobic perpendicular nanopin film by the bottom-up process. J. Mater. Chem. 15, 1938-1945 (2005). 